\title{
Community Volunteer Service System of University of Alberta and Its Enlightenment
}

Xun Wang

University of Electronic Science and Technology of China, Chengdu 610054, China

\begin{abstract}
Social harmony and progress are inseparable from the development of university students 'volunteer service. After analyzing the community volunteer service system of University of Alberta in Canada, suggestions are put forward for the development of university students' voluntary service in terms of curriculum, brand, motivation and research.
\end{abstract}

Keywords: Volunteer service; University student; University of Alberta

\section{阿尔伯塔大学社区志愿者服务体系与启示}

\section{王勋}

电子科技大学物理电子学院，四川省成都市 610054

摘要: 社会的和谐与进步离不开大学生志愿服务的发展, 经过对加拿大阿尔伯塔大学社区志愿者服务体系的分析, 从 课程、品牌、激励以及研究等方面对国内高校大学生志愿服务发展提出了建议。

关键词: 志愿服务; 大学生; 阿尔伯塔大学

中图分类号: G64

文献标识码: A

\section{1 引言}

志愿服务是促进社会和谐与进步的重要标志与途径。2013 年 12 月, 习近平总书记给华中农业大学 “本禹志愿服务队” 回信, 肯定他们在服务他人、奉献社会中收获的成绩和进步，希望他们弘扬志愿精 神, 坚持与祖国同行, 为人民奉献[1]。2014 年, 教育部联合团中央出台了《关于在各级各类学校推动培 育和践行社会主义核心价值观长效机制的意见》, 明确提出要建立健全学生志愿服务体系、评价体系和保 障体系。2015 年, 教育部出台《学生志愿服务管理暂行办法》, 强调建立健全学生志愿服务工作体系、评 价体系和保障体系，增强学生社会责任感。十九大报告指出推进诚信建设和志愿服务制度化，强化社会 责任意识、规则意识、奉献意识。

\section{2 大学生志愿服务的重要性}

大学生志愿服务在近年来蓬勃兴起, 志愿者队伍逐渐壮大, 2012 年以来大学生参加志愿服务累计 1000 余万人次, 在北京奥运会、上海世博会、广州亚运会、深圳大运会等重大活动中发挥了重要作用, 充分得到了社会的肯定。大学生志愿者服务的重要性体现在以下几个方面：第一，有助于实现大学生的 精神需求, 大学生志愿服务满足了大学生在自我实现和赢得尊重等方面的精神需求, 使个人的精神境界 得到升华; 第二, 有助于提高大学生综合素质, 大学生通过志愿服务学习知识和技能, 增强社会责任感, 提高合作竞争能力、组织协调能力、创造能力、社会适应能力、社会交往能力等，全面提高大学生的综 合能力; 第三，有助于推进社会和谐与进步，大学生志愿服务走进社区, 弘扬正气，传播爱心和文明，以 
其特有的感召力和影响力提高公民的整体素质, 有助于构建社会主义和谐社会 [2]。

\section{3 阿尔伯塔大学社区志愿服务体系}

2016 年 6 月, 阿尔伯塔大学学术委员会和董事会一致通过了新的大学战略规划 “为了公众利益”。 它充分展现了大量毕业校友、大学志愿者、战略伙伴和其它利益相关者对学校的有力支持。阿尔伯塔大 学也致力于深化与他们的联系, 在他们的帮助下共同实现 “为了公众利益” 的目标。早在阿尔伯塔大学 成立的初期, 学校的教授和员工们就积极的到广大农村社区传授各类知识, 从莎士比亚文学到农业生产 的作业流程。从那时开始, 阿尔伯塔大学就深深的融入到远近的社区之中。在 1908 年, 创校的第一任校 长亨利 -马歇尔 - 托里对阿尔伯塔人说到 “现代公立大学的产生源于人们自身的需求”, 并承诺道 “知 识不应仅仅是学者的追求。提升全体人民才是大学存在的最终目标”。他向未来的后辈们提出了挑战, 教他们不要忘记这个终极目标。

阿尔伯塔大学的发展规划提出要加强和维护互惠互利的社区关系, 加强与社区的交流, 开展社区研 究, 从而扩大大学对社会的影响、价值和有效性。学校与社区的关系的重要支撑与桥梁就是大学生社区 志愿服务。

\section{1 社区服务学习课程}

阿尔伯塔大学开设的社区服务学习课程使学习变得活跃起来。学习将学术课程与基于社区的经验联 系起来。大学生将他们的时间和才华带到社区组织, 作为他们学习的一部分, 挑战他们以新的方式参与 他们的学业, 探索理论与实践之间的关系。社区服务学习课程通过持续和协作的过程集成到课程中。社 区合作伙伴描述他们的志愿者和研究需求给我们, 和导师设计他们的课程项目和目标, 把这些社区的经 验融入课程的学生。

通过这个课程, 大学生能发展个人的批判性思维, 解决问题的技能, 以及提高沟通, 协作和领导能 力; 能提高对课程材料的理解, 并学会将课程材料应用到新的情境中; 获得在非盈利部门实践的实际经验; 以及更多地了解社会问题及其根源。通过这个课程, 教师获得活跃的课堂、教育学的新观点以及与社区 组织的联系; 并能学习互动式教学方法, 促进学生的主动学习了解社区问题的第一手知识; 还是探索合作 工作和研究机会的新途径。社区通过这个课程对大学生的精力和能力有了新的认识, 发展了现有的或新 的项目, 建立了与大学的联系, 并有机会成为联合教育者; 还能获得实现组织目标所需的额外人力资源; 同时提高公众对关键问题的认识; 以及识别和访问其他大学资源。大学通过这个课程促进公民参与, 培养 大学生领导能力; 鼓励教师、学生和社区的互动与协作; 发展和加强大学与社区的关系; 以及在校园和更广 泛的社区中嵌入发现学习体验。

\section{2 社区帮助项目}

社区帮助项目是为员工和学生免费提供的培训项目。社区志愿者工作团队在学生处的监督下, 为各 年龄段、群体、背景和收入水平的大学生提供支持, 使他们相互联系, 成为校园社区, 以及校园内外的 资源; 同时社区志愿者工作团队在大学生在校以及之后发展中协助介绍、培训和社区活动，使大学生聚 集在一起, 建立社区, 减少孤独感, 锻炼能力。社区教育促进和促进学生、教职员工和教员的学习和发 展机会; 社区建设识别和加强社区内现有的资产; 社区外联和资源加强社区成员与服务和资源的联系; 社区激励协助社区成员自我激励。利用社区实践原则, 通过培养校园社区成员之间的联系和恢复能力来 
改善校园的福祉, 包括识别个人力量、培养人际关系和创造健康的社区。社区志愿者们为年轻人提供 " 正式” 和 “非正式”支助的桥梁, 侧重于预防和及早识别可能有危险的年轻人; 提供资源、联系和支持方 面的广泛培训, 为社区能力建设提供了一个模型, 涉及青年心理健康促进问题; 通过提高社区意识减少污 名, 扩大关于心理健康问题的知识，并为那些可能有自杀风险的人改进干预措施。

社区志愿者项目将研究生、学者、博士后和所有学科的校友联系到中小学和大社区的学生, 分享他 们的研究知识和经验, 激励明日的领导人和思想家。无论是参观学校、参加科学博览会还是举办人文会 议, 每年约有 470 志愿人员职位可供约 58 个活动之用。研究生志愿者可以获得学术认可, 这些活动可以 用于奖学金和奖项评比; 还可以获得实际的教学经验, 开发一个创造性的方法, 完善研究报告和建立信 心; 同时与其他研究人员和雇主联系, 在自己研究领域获得新的兴趣和机会; 研究生志愿者们还能得到八 小时的专业培训。

\section{3 社区-大学合作伙伴关系研究中心}

社区和大学有许多共同利益。双方都希望改进知识, 以不同的方式分享知识, 并为以证据为基础的 政策和做法作出贡献, 使儿童和家庭得到最佳的利益。他们都具有追求这些利益的专门知识和资源, 两 者都认识到他们的专长和资源是不完整和有限的。埃德蒙顿社区和大学的成员产生了一个研究中心的想 法, 因为他们认识到, 如果他们都要负责任地追求自己的目标, 他们需要在共同关心的领域分享专长和 资源。

社区-大学合作伙伴关系研究中心研究社区的儿童、青年和家庭和大学的伙伴关系, 努力改善儿童、 青年、家庭和社区的福祉, 在埃德蒙顿和阿尔伯塔的社区成员、研究人员、从业者、社区组织、资助者 和决策者之间建立独特合作。中心的研究目标是创造、分享和调动知识, 使之能够告知政策、实践和评 估，以促进儿童、青年和家庭的发展。每个项目都是通过创新的基于社区的研究伙伴关系指导的，其中 包括来自不同部门和学科的社区和大学伙伴。中心通过反思、评价和学习来驱动改进和创新, 进而改进 实践、计划和政策。真正的合作、参与以及社区和大学合作伙伴之间的共同领导是中心工作的关键基础。 社区的合作伙伴带来各种知识、价值观、社会规范、文化背景和环境，为研究及其成果作出贡献。

\section{4 社区服务奖励}

社区服务奖励表彰那些致力于社区志愿服务的人, 并对社区和大学产生积极影响的人, 体现了阿尔 伯塔大学承诺的 “为了公众利益” 的精神。比如 2017 年社区服务领导奖的获奖者大学健康中心护理团队。 在麦克默堡的大规模野火之后, 当超过 1200 灾民在李斯特霍尔避难时, 大学健康中心护理队是校园内动 员的首批团体之一。该小组迅速设立了一个分流站, 为那些生活被大火摧毁的流离失所者提供必要的医 疗和情感支持。随着危机的进展, 护理团队动摇, 利用自己的时间和资源, 确保药物和供应。他们的献 身精神是在阿尔伯塔大学欢迎和支持麦克默堡撤离人员的重要组成部分。

\section{4 大学生志愿服务的几点思考}

\section{1 开展志愿服务课程, 提升大学生志愿服务的专业含量}

阿尔伯塔大学通过社区服务学习课程, 让学生系统化的开展志愿服务, 并在活动中实践和学习, 在 志愿服务中不断提升自身专业知识。

高校要为大学生志愿者量身定制适合的培训课程, 要论证大学生志愿服务课程的可行性, 注意把知 
识培训与实践培训结合起来，做到论证充分、定位准确、方向明晰; 讲授志愿服务的基础知识、专业技 能、管理方法, 提升志愿者对突发事件的处理能力; 要结合大学生的特点, 根据公众的需要和社会发展研 究制定专项的志愿服务课程。高校还可以搭建大学生志愿服务网络平台, 开展网上志愿服务课程, 让志 愿者定期分享经验，推进志愿服务交流。

大学生具有专业功底较厚、文化层次高、创新能力较强的特点, 是一个特殊的知识群体, 运用自己 所学知识为社会服务是活动保持旺盛生命力的关键, 是大学生志愿服务活动的重要特征。高校要突出专 业特色, 以大学生所学专业为基础科学合理安排志愿服务, 提升大学生志愿服务的专业技能含量; 要积极 引导和鼓励大学生在开展志愿服务活动中把志愿服务和专业学习有机结合起来, 充分发挥自己的专业优 势, 形成专业知识学习与志愿服务实践的良性循环 ${ }^{[3]}$ 。

\section{2 打造志愿服务品牌, 树立大学生志愿服务的价值观}

阿尔伯塔大学社区志愿服务品牌项目已经运行了几十年, 大学生在这些项目中整合资源, 完成自我 激励, 形成社区服务的氛围, 增强大学生志愿服务的意识, 建立了志愿服务的价值观。

高校要科学设计志愿服务的形式和内容, 使得活动形式有效多样, 打造志愿服务品牌。大学生志愿 服务要想有品牌效应, 必须有稳定的志愿服务基地, 高校应结合经济社会发展急需的行业和领域, 发挥 人才、知识、技能、学科、专业等优势, 建立志愿服务基地; 大学生志愿服务要想有品牌效应, 必须有 自己的特色, 高校以受助方的需求为导向, 结合学校的办学特色和大学生的专业特点, 逐步建立大学生 志愿服务的品牌; 大学生志愿服务要想有品牌效应, 还必须确保志愿服务活动过程的连续性。高校要根 据大学生群体周期流动的特点, 完善志愿者招募机制, 让更多的大学生参与志愿服务, 使志愿服务有长久 的发展动力。

高校要大力弘扬 “奉献、友爱、互助、进步” 的志愿精神, 在全社会形成良好與论氛围, 提高全社 会对大学生志愿服务活动的认识, 为大学生在志愿服务的实践中做贡献构建宽广平台。高校要鼓励大学 生参与志愿服务, 强化大学生的自愿性和成就感; 帮助大学生在志愿服务中树立对人民的感情、对社会 的责任、对国家的忠诚的核心价值观, 激发大学生参加志愿服务的热情 ${ }^{[4]}$ 。

\section{3 完善志愿服务激励机制, 加强大学生志愿服务的研究}

阿尔伯塔大学社区服务奖励大会每年举行, 对社区成员、教职员工、学生或博士后研究员通过义工、 公众演讲、学校探访或其它杰出的社区志愿服务产生积极影响的个人或团队进行表彰。阿尔伯塔大学有 专门的社区志愿服务的研究机构, 对如何维护大学与社区的伙伴关系, 开展大学生志愿服务等开展深入 研究。

高校要完善志愿服务激励机制。高校可以将大学生的志愿服务记录归入学生综合素质档案, 并作为 大学生志愿服务经历鉴定的重要依据; 借鉴国外大学的经验, 把志愿服务纳入大学生培养体系当中, 把 经过学校认证的志愿服务纳入实践学分管理; 根据大学生志愿者参加志愿服务的时间累计, 实行认证志 愿者为一到五星的星级认证制度。高校要每年评选、奖励表现突出的大学生志愿者和志愿服务组织, 颁 发相应的证书, 给予专项的奖励; 同时积极开展志愿服务先进典型宣传, 集中展示大学生志愿者的风采。

高校要针对志愿服务的发展开展科学研究, 推进志愿服务的需求方、组织方、实施方的相互协作, 为 促进国民素质的提高和推动社会的全面进步发挥积极作用，为社会经济持续快速发展作贡献。 


\section{参考文献:}

[1] 习近平给华中农业大学 “本禹志愿服务队” 回信勉励青年志愿者以青春梦想用实际行动为实现中国梦作出新的更 大贡献 [N]．人民日报, 2013-12-06(1).

[2] 潘艳艳. 高校志愿服务发展研究 [D]. 苏州大学硕士学位论文 , 2013：9-10.

[3] 贺贝贝. 研究生志愿服务可持续发展面临的问题和对策 $[\mathrm{J}]$. 中国电力教育, 2010(5)：179-180.

[4] 薛志谦．基于创新创业思维的大学生志愿服务常态化路径研究 [J]．当代青年研究，2016 (5)：30-31.

\section{References}

[1] Xi Jinping Huazhong Agricultural University, "Ben Yu Volunteer Team," wrote a reply to encourage young volunteers to use their dreams of youth dreams to make new and greater contribution to the realization of the Chinese dream [N]. People's Daily, 2013-12-06 (1).

[2] Pan Yan-yan: University Volunteer Service Development (MS.,Suzhou University, China 2013),p.9-10.

[3] He Bei-bei: "Problems and countermeasures of sustainable development of graduate volunteer service" [J] .Electric Power Education in China, 2010,No.5,p.179-180(in Chinese)

[4] Xue Zhi-qian: "Study on the normalization path of college students volunteer service based on the idea of innovation and entrepreneurship" [J] .New Youth Research, 2016,No.5,p.30-31 (in Chinese) 